\title{
Neuroimaging findings of Zika virus infection: beyond the brain CT scans
}

\author{
Alfonso J. Rodriguez-Morales ${ }^{1,2}$
}

Received: 3 November 2016 / Accepted: 9 November 2016 / Published online: 28 November 2016

(C) Japan Radiological Society 2016

\section{Dear Editor,}

Although from a theoretical point of view, the article by Zare Mehrjardi et al. [1] is interesting, given that it is a review article on neuroimaging, it would be good to have not only images of brain CT scans of Zika cases, but also ultrasound, MRI, and even X-ray. A table summarizing the main findings of each of the alterations at each study would be useful, especially for orientation of the physicians, radiologists and neuroradiologists who will now face the interpretation of such imaging studies in cases with suspected or confirmed Zika virus infection, particularly given that neuroimaging may be of great help in providing answers and gaining a better understanding of the congenital Zika syndrome [2].

Especially during pregnancy, the use of ultrasound would be emphasized, as recent studies show that associated intracranial anomalies would be detected in the majority of fetuses with microcephaly, and that a significant proportion of these would be found with an estimated fetal weight below the 10th percentile at the ultrasound examination [3].

Certainly, many questions remain on multiple clinical aspects of Zika, which has become in a major threat, especially in Latin America [4], where the congenital infection has been reported in a significant number of cases, particularly from Brazil [3].

\section{Compliance with ethical standards}

Conflict of interest The author declares that he has no conflict of interest.

\section{References}

1. Zare Mehrjardi M, Keshavarz E, Poretti A, Hazin AN. Neuroimaging findings of Zika virus infection: a review article. Jpn J Radiol. 2016;. doi:10.1007/s11604-016-0588-5.

2. Poretti A, Huisman TA. Neuroimaging findings in congenital Zika syndrome. Am J Neuroradiol. 2016;. doi:10.3174/ajnr. A4924.

3. Carvalho FH, Cordeiro KM, Peixoto AB, Tonni G, Moron AF, Feitosa FE, Feitosa HN, Araujo Júnior E. Associated ultrasonographic findings in fetuses with microcephaly because of suspected Zika virus (ZIKV) infection during pregnancy. Prenat Diagn. 2016;36(9):882-7.

4. Rodriguez-Morales AJ. Zika: the new arbovirus threat for Latin America. J Infect Dev Ctries. 2015;9(6):684-5.

This comment refers to the article available at doi:10.1007/s11604-016-0588-5.

Alfonso J. Rodriguez-Morales

arodriguezm@utp.edu.co

1 Public Health and Infection Research Group, Faculty of Health Sciences, Universidad Tecnológica de Pereira, Pereira, Risaralda, Colombia

2 Colombian Collaborative Network on Zika (RECOLZIKA), Pereira, Risaralda, Colombia 